\title{
The Effects of Hot Deformation Parameters on the Size of Dynamically Recrystallized Austenite Grains of HSLA Steel
}

\author{
Sebastian Gnapowski', Marek Opiela², Elżbieta Kalinowska-Ozgowicz', \\ Joanna Szulżyk-Cieplak ${ }^{*}$ \\ 1 Fundamentals of Technology Faculty, Lublin University of Technology, ul. Nadbystrzycka 38D, 20-618 Lublin, \\ Poland \\ 2 Faculty of Mechanical Eengineering, Silesian University of Technology, ul. Konarskiego 18a, 44-100 Gliwice, \\ Poland \\ * Corresponding author's e-mail: j.szulzyk-cieplak@pollub.pl
}

\begin{abstract}
Materials scientists are seeking to produce metals with reduced weight and dimensions while maintaining the appropriate mechanical properties. There are several ways to improve the internal structure of metals, such as the ultrasound used to solidify liquid metal. The homogeneity of the grains and the uniformity of the metal structure affects its mechanical strength. This paper presents the results of investigations into the effects of hot deformation parameters in compression on the austenite grain size in the HSLA (High Strength Low Alloy) steel $(0.16 \% \mathrm{C}, 0.037 \% \mathrm{Nb}, 0.004 \%$ $\mathrm{Ti}, 0.0098 \% \mathrm{~N})$. The axisymmetric compression investigations were performed on cylindrical investigation specimens using a Gleeble 3800 thermomechanical simulator with the strain rate of $1 \div 15.9 \mathrm{~s}^{-1}$ and strain degree $\varepsilon=1.2$. Before deformation, the research specimens were austenitized at $\mathrm{T}_{\mathrm{A}}=1100 \div 1250{ }^{\circ} \mathrm{C}$. The metallographic observations of the primary austenite grains were conducted with an optical microscope, while the structure of dynamically recrystallized austenite, inherited by martensite, was examined by using a scanning electron microscope.
\end{abstract}

Keywords: HSLA steel, dynamic recrystallization, austenite grain, plastic strain, Gleeble simulator

\section{INTRODUCTION}

The possibility of full control of the grain size, and hence the production of products with a fine grain structure are demonstrated by HSLA (High Strength Low Alloy) containing micro-additives with high affinity with carbon and nitrogen, such as $\mathrm{Nb}$, Ti and $\mathrm{V}$. The metallic micro-additives added to these steels interact with $\mathrm{C}$ and $\mathrm{N}$ to form stable interstitial phases MX (M - Nb, Ti, V; X - N, C). The stability of these phases depends mainly on their chemical composition, while the temperature of their dissolution can vary widely. In the technological process of producing steel products, this allows for obtaining various structural effects, such as: controlling the austenite grain size at high temperature by undissolved particles of precipitates, changing the kinetics of recrystallization and phase changes caused by dissolved elements and precipitation, as well as obtaining the effect of strengthening by low dispersive discharge temperature. Dispersive particles of interstitial phases type MX, such as carbides, nitrides and carbonitrides, introduced into the micro-additives steel, inhibiting the movement of grain boundaries of recrystallized austenite, create the possibility of producing metallurgical products with high mechanical properties [30-33]. The condition for obtaining metallurgical products with high mechanical properties from micro-alloy steel is the proper selection of plastic forming conditions, adapted to the separation process of MX type interstitial phases [15, 37]. In microalloyed steels, the effect of MX-type phase particles on dynamic recrystallization depends on their size, shape and distribution in the matrix. If the MX-type phase particles are fine and of high dispersion, they stabilize substructure, hinder the formation of recrystallization 
fronts and their migration and inhibit dynamic recovery. As a result, the impact of such particles inhibits dynamic recrystallization and may result in significant grain refining. In contrast, when the second phase particles are precipitated within the grain boundaries, they can effectively block their migration, that is inhibit dynamic recrystallization without significantly affecting dynamic recovery. For large second phase particles that interact with dislocations as stress concentrators and are also privileged points for heterogeneous formation of recrystallization nuclei, the acceleration of dynamic recrystallization is observed [20-23, 35].

Hot deformation parameters have a decisive impact on the formation of secondary phases of microadditions that determine the course of dynamic recrystallization and structure refinement in HSLA steels [1, 2, 39]. Many strategies have been adopted to improve the ductility and impact properties of these ultrahigh-strength DP (Dual Phase) steels, such as refining of microstructure, alloying, or designing new processing methods $[6,19,28]$. HSLA steel has better mechanical properties, including high strength, and better corrosion resistance than carbon steel $[4,11,12,45]$. Mechanical properties are usually determined by chemical composition and thermo mechanical treatments $[10,13,25,27,36,38,44]$. Nevertheless, final mechanical properties are observed to depend on the fraction of reverted austenite, which is very sensitive to heat treatment $[3,8,16,24,29,41]$.

Meeting the growing requirements of steel customers related to the increase in strength while maintaining the required ductility is seen in the full use of micro-additives. In the case of HSLA micro-alloy steels, the increase in strength is associated with grain grinding and precipitation hardening by $\mathrm{Nb}$, Ti and $\mathrm{V}$ carbide, nitride and carbonitride nitrides. The analysis of the literature indicates that the conducted research in a significant number of cases focus on the introduction of micro-additive $\mathrm{V}[14,17,26,34,40]$ and $\mathrm{Ti}$ and $\mathrm{V}[7,9,18,42,43]$. Much less work concerns the overall introduction to steel to $\mathrm{Nb}, \mathrm{Ti}$ and $\mathrm{V}$ steel. The purpose of this work is to investigate the impact of temperature and strain rate on the size of austenite grains of dynamically recrystallized HSLA steel with $\mathrm{Nb}$, Ti and $\mathrm{V}$ micro-additives.

\section{MATERIALS AND METHODS}

The investigations were carried out on the HSLA steel grade S355NL from the industrial process with the chemical composition as presented in Table 1.

The plastometric investigations with the axisymmetric hot compression method were carried out for HSLA steel to determine the effect of the austenitizing temperature and the strain temperature, as well as the degree and rate of the $\sigma-\varepsilon$ flow curves, which represent thermally activated processes that take place in the material being deformed and determine the change in structure, in particular with regard to the size of austenite grain. The axisymmetric hot compression investigations were carried out on cylindrical research specimens of $7 \mathrm{~mm}$ in diameter and $8.4 \mathrm{~mm}$ in length using a Gleeble 3800 simulator.

The research specimens were heated in the simulator by the resistance method, in an argon atmosphere. To reduce the coefficient of friction, the investigation specimens' faces were coated with graphite and tantalum foil. Continuous compression experiments were carried out to $\varepsilon=1.2$ on research specimens austenitized in a temperature range of $1100 \div 1250^{\circ} \mathrm{C}$ and deformed in a temperature range of $800 \div 1250^{\circ} \mathrm{C}$ at a strain rate of approximately $1.0 \mathrm{~s}^{-1}, 3.6 \mathrm{~s}^{-1}, 9.55 \mathrm{~s}^{-1}$ and $15.9 \mathrm{~s}^{-1}$. Immediately after the compression investigation, the research specimens were cooled in water to freeze the effects of hot plastic deformation. The metallographic microscopic examinations were carried out on longitudinal microsections of hot compressed and water- or air-cooled research specimens.

The structure observations were carried out with an Olympus GX71 microscope at magnifications of up to approximately $2000 x$ and optionally in polarised light. In order to reveal the primary austenite grains, etching with saturated aqueous solution of picric acid at $70^{\circ} \mathrm{C}$ was used. In other cases, the microsections were etched with a reagent

Table 1. Chemical composition of HSLA steel under investigation

\begin{tabular}{|c|c|c|c|c|c|c|c|c|c|}
\hline \multicolumn{10}{|c|}{ Element concentrations, wt \% } \\
\hline $\mathrm{C}$ & $\mathrm{Mn}$ & $\mathrm{Si}$ & $\mathrm{P}$ & $\mathrm{S}$ & $\mathrm{Ti}$ & $\mathrm{Nb}$ & $\mathrm{V}$ & $\mathrm{Al}$ & $\mathrm{N}$ \\
\hline 0.16 & 1.48 & 0.29 & 0.030 & 0.017 & 0.004 & 0.037 & 0.002 & 0.010 & 0.0098 \\
\hline
\end{tabular}


(nital). The measurement of the average diameter of the primary austenite grain was performed according to norm ASTM E112-10 [46] by counting the number of intersections on at least seven representative fields of observation. The results of these measurements were developed statistically for a confidence interval of $\mathrm{P}=0.95$. Were carried out to determine the structure of austenite inherited by martensite by using a scanning electron microscope Inspect F with a Schottky field emission gun.

\section{RESULTS}

In the conducted experiments, the steel microalloyed with $\mathrm{Ti}, \mathrm{Nb}$ and $\mathrm{N}$, deformed in hightemperature compression investigation to $\varepsilon=1.2$, revealed flow curves of different waveforms, dependent mainly on the austenitizing temperature as well as the strain temperature and rate (Figure 1).

After austenitizing at $\mathrm{T}_{\mathrm{A}}=1250^{\circ} \mathrm{C}$ and $1200^{\circ} \mathrm{C}$ and deformation in a temperature range of $\mathrm{T}_{\text {def }}=$ $1100 \div 1250^{\circ} \mathrm{C}$ at a rate between $1.0 \mathrm{~s}^{-1}$ and $15.9 \mathrm{~s}^{-}$ ${ }^{1}$, the recorded $\sigma-\varepsilon$ curves are characterized by the occurrence of more or less distinct maximum flow stress and a limited scope of fixed stresses, determined by the course of dynamic recrystallization (Figure 1-3).

At a lower deformation temperature (900 and $1000{ }^{\circ} \mathrm{C}$ ), dynamic recrystallization is not seen (Figure 1a, 1b). As the deformation $(\varepsilon=$ 1.2) achieved in the compression experiment performed is too small to trigger the dynamic recrystallization process in the investigated steel. Under such deformation conditions, dynamic recovery is the decisive process that removes the effects of strain hardening.

At a higher deformation temperature $\left(1100 \div 1250{ }^{\circ} \mathrm{C}\right)$, the $\sigma-\varepsilon$ curves show a slight reduction in flow stress value (Figure 3). The $\varepsilon_{\mathrm{m}}$ values on the $\sigma-\varepsilon$ curves decrease as the strain temperature increases and the strain rate decreases. The changes in the flow stress of the investigated hot-deformed steel depend significantly on the strain temperature and strain rate, but do not depend clearly on the austenitizing temperature within the investigated range $\left(1250 \div 1100{ }^{\circ} \mathrm{C}\right)$. The maximum stress values in the steel after austenitizing and deformation at $1200{ }^{\circ} \mathrm{C}$ increase from $78.8 \mathrm{MPa}$ to $115.6 \mathrm{MPa}$ along with increase in the strain rate in the range between $1.0 \mathrm{~s}^{-1}$ and $15.9 \mathrm{~s}^{-1}$ (Figure 2b). After austenitizing at 1200 a)

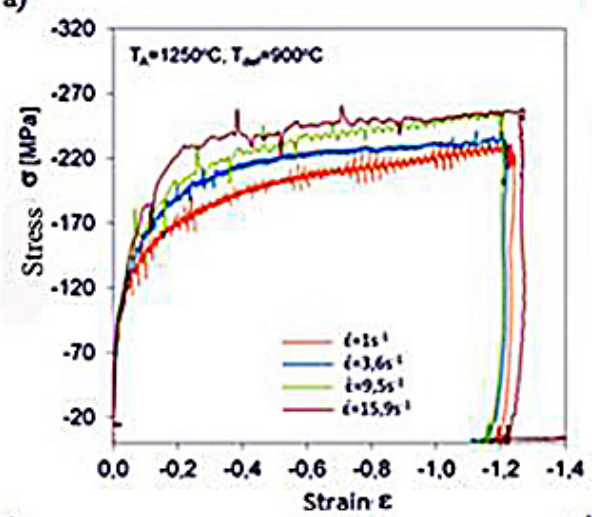

c)

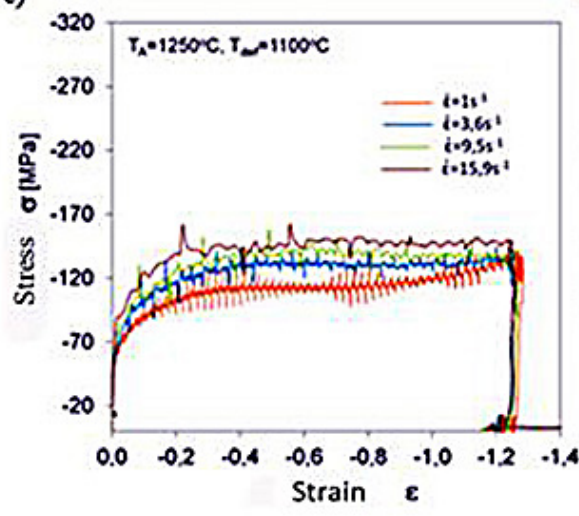

b)

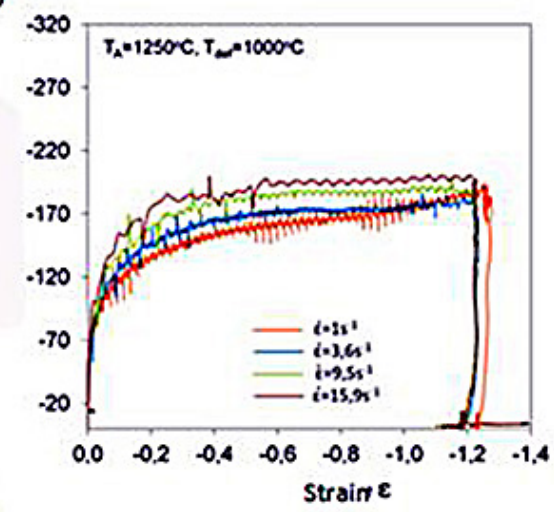

d)

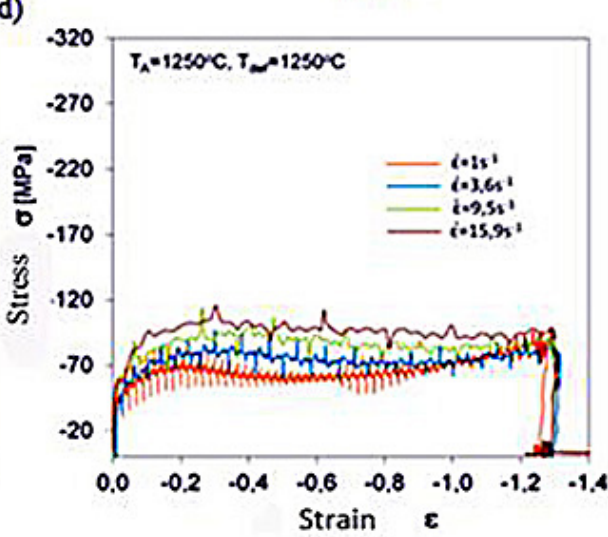

Figure 1. The effect of strain temperature and strain rate in compression investigation on flow curves of the investigated steel austenitized at $1250^{\circ} \mathrm{C}, \mathrm{T}_{\text {def: }}$ : a) $900^{\circ} \mathrm{C}$, b) $1000^{\circ} \mathrm{C}$, c) $1100^{\circ} \mathrm{C}$, d) $1250 \mathrm{~V}$ 

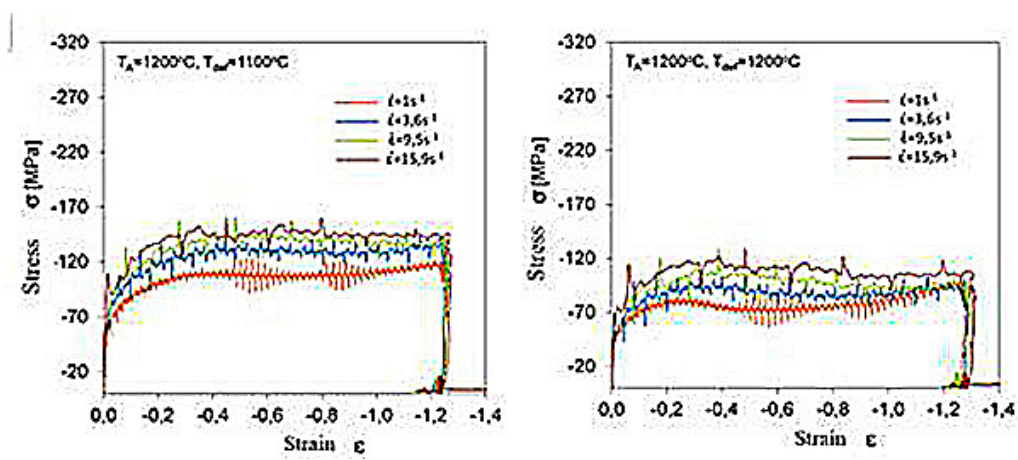

Figure 2. The effect of strain temperature and strain rate in compression investigation on flow curves of HSLA steel austenitized at $1200{ }^{\circ} \mathrm{C}, \mathrm{T}_{\text {def }}$ : a) $1100{ }^{\circ} \mathrm{C}$, b) $1200^{\circ} \mathrm{C}$
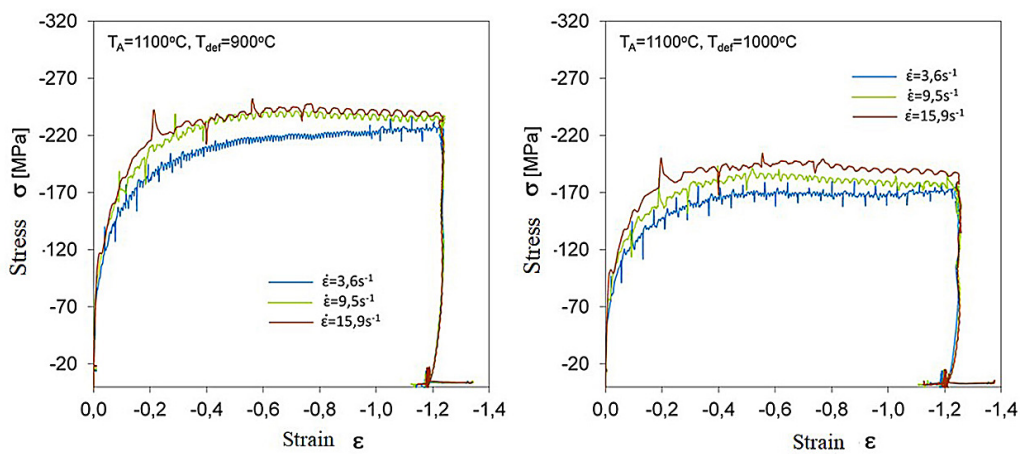

Figure 3. The effect of strain temperature and strain rate in compression investigation on the flow curves of microalloyed steel austenitized at $1100^{\circ} \mathrm{C}, \mathrm{T}_{\text {def }}$ a) $900^{\circ} \mathrm{C}$, b) $1000^{\circ} \mathrm{C}$

${ }^{\circ} \mathrm{C}$ and deformation at $1100{ }^{\circ} \mathrm{C}$ while at the same maintaining the same rate, the $\sigma_{\max }$ values increase from $108 \mathrm{MPa}$ to $151 \mathrm{MPa}$ (Figure 2a).

The metallographic examinations carried out allowed the effect of high-temperature deformation parameters on the size and shape of the primary austenite grain $\left(\mathrm{d}_{\mathrm{o}}\right)$ before $\mathrm{g} \rightarrow \mathrm{a}$ ' transition conditioned by the course of thermally activated processes to be determined. It was found that austenitizing temperature had a decisive impact on the austenite grain size before high-temperature deformation (Figure 4). The investigated steel austenitized at $1100^{\circ} \mathrm{C}$ reveals austenite grains of $d_{o}=36 \mu \mathrm{m}$ (Figure $\left.4 \mathrm{a}\right)$. The increase in austenitizing temperature up to $1200{ }^{\circ} \mathrm{C}$ or $1250^{\circ} \mathrm{C}$ results in an increase in the primary grain size $\gamma$ up to approximately $76 \mu \mathrm{m}$ or $83 \mu \mathrm{m}$, respectively (Figure 4c). After the steel has been cooled down from this austenitizing temperature range in water, lath martensite with bainite areas (Figure $4 b$, d) and various lath sizes were revealed in the microstructure of the investigated steel.

The microphotograph (Figure 5) shows the results of metallographic observations of microalloy steel that has been deformed plastically in compression investigation at a strain rate of approx. $1.0 \mathrm{~s}^{-1}$ and a constant strain degree $(\varepsilon=1.2)$ in a temperature range of $1200 \div 800{ }^{\circ} \mathrm{C}$ after austenitizing at $1200^{\circ} \mathrm{C}$. Primary austenite grains of varying sizes and forms depending on strain temperature were revealed in the structure of HSLA steels. Deformation at $1200{ }^{\circ} \mathrm{C}$ and $1100{ }^{\circ} \mathrm{C}$ allows the dynamically recrystallized $\gamma$ grains of approx. $16.1 \mu \mathrm{m}$ (Figure 5a) and approx.10 $\mu \mathrm{m}$ (Figure $5 \mathrm{~b}$ ), respectively, to be obtained within the entire material volume (Table 2).

The advantageous effect of refining $\gamma$ grains while maintaining their high dimensional uniformity and equiaxiality is shown clearly in the microphotograph (Figure 5b). After deformation at 1000 ${ }^{\circ} \mathrm{C}$, fine recrystallized $\gamma$ grains were revealed in the near-boundary areas and occasionally within the primary austenite grains as a result of the initiation of dynamic recrystallization (Figure $5 \mathrm{c}$ ), while after deformation at $800{ }^{\circ} \mathrm{C}$, clearly elongated primary austenite grains with a number of deformed twins and slip bands, which are characteristic of the hardening stage on $\sigma-\varepsilon$ flow curves with a small contribution of thermally-activated processes, primarily dynamic recovery, were revealed (Figure 5d).

The additive effect of strain temperature and strain rate in the austenitizing temperature range $\left(1250{ }^{\circ} \mathrm{C}, 1200{ }^{\circ} \mathrm{C}\right)$ on the structure of primary austenite grains of the investigated steel is shown 
a)

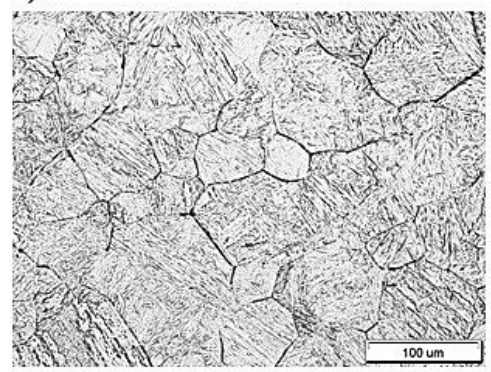

c)

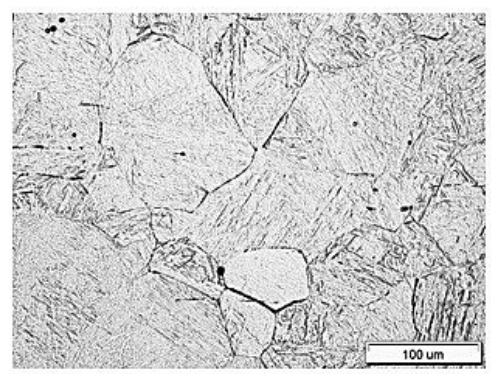

b)

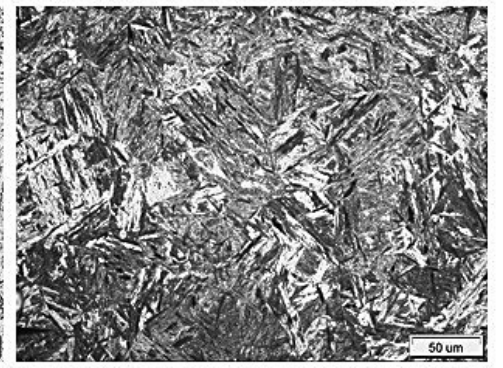

d)

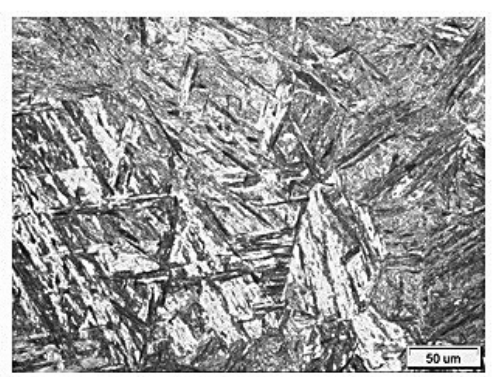

Figure 4. Structure of the investigated steel after austenitizing at: a, b) $1100{ }^{\circ} \mathrm{C}$; c, d) $1250^{\circ} \mathrm{C}$; primary austenite grain size $(\mathrm{a}, \mathrm{c})$, martensitic - bainitic structure $(\mathrm{b}, \mathrm{d})$

a) b)
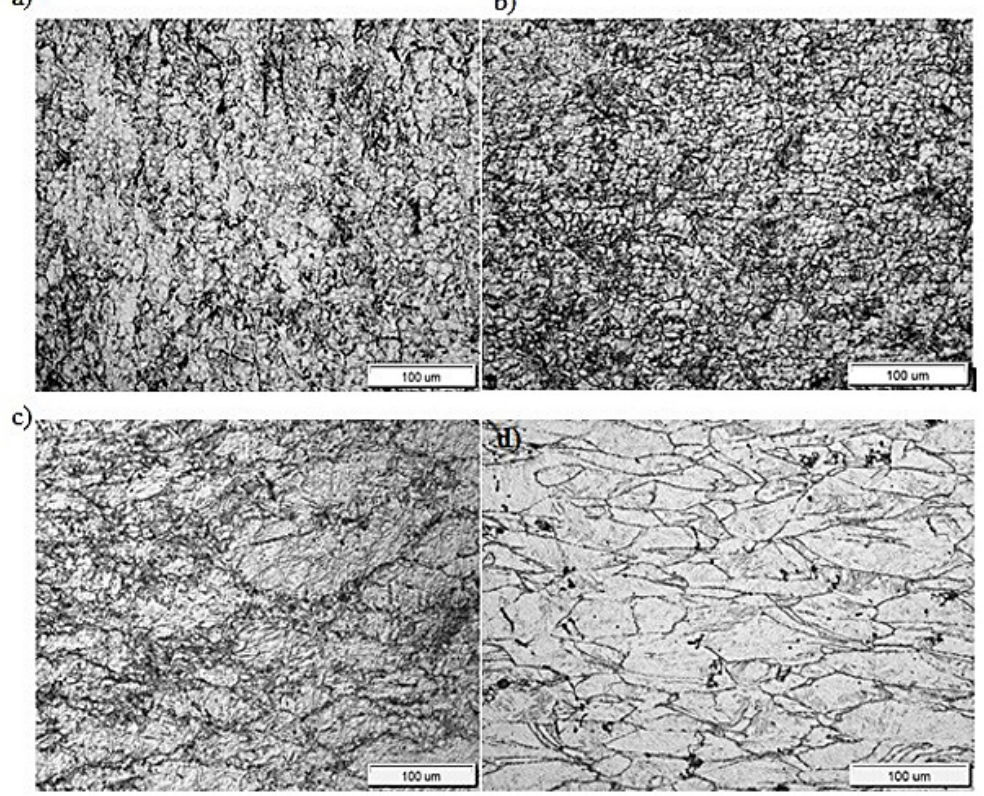

Figure 5. The effect of strain temperature at a strain rate $=1.0 \mathrm{~s}^{-1}$ on the structure of primary austenite grains of the investigated steel: a) $1200{ }^{\circ} \mathrm{C}$, b) $1100{ }^{\circ} \mathrm{C}$, c) $1000^{\circ} \mathrm{C}$, d) $800{ }^{\circ} \mathrm{C}\left(\mathrm{T}_{\mathrm{A}}=1200{ }^{\circ} \mathrm{C}, \varepsilon=1.2\right)$

in (Figure 6,7). The increase in strain rate up to approx. $15.9 \mathrm{~s}^{-1}$ causing the effect of delayed dynamic recrystallization of the investigated steel, recorded on the flow curves, also affects the microstructure of primary $\gamma$ grains in the analyzed strain temperature range (Figure 6). At a comparable strain temperature of $1100{ }^{\circ} \mathrm{C}$ and strain degree $(\varepsilon$ $=1.2$ ), the primary austenite grains of the investigated steel deformed at a rate $1.0 \mathrm{~s}^{-1}$ are completely dynamically recrystallized (Figure 5b), while those deformed at a rate $3.6 \mathrm{~s}^{-1}$ only show partial dynamic recrystallization (Figure 7a). A similar effect of changes in microstructure of primary $\gamma$ grains is observed for a strain temperature of $1000^{\circ} \mathrm{C}$ and a strain rate of $3.6 \mathrm{~s}^{-1}$ or $15.9 \mathrm{~s}^{-1}$ (Figure 6). In (Figure $7 \mathrm{~b}$ ), austenite after dynamic deformation $\left(\mathrm{T}_{\mathrm{A}}=\right.$ $1200^{\circ} \mathrm{C} \mathrm{T}_{\text {def }}=900^{\circ} \mathrm{C}, \varepsilon=1.2$ ) reveals a microstructure of elongated grains with deformed twins inside them and fine dynamically recrystallized grains mostly at the boundaries of former primary 
Table 2. Average primary austenite grain diameter

\begin{tabular}{|c|c|c|c|c|}
\hline $\begin{array}{c}\text { Austenitizing temperature, } \\
{ }^{\circ} \mathrm{C}\end{array}$ & $\begin{array}{c}\text { Average grain diameter } \\
\mathrm{d}_{\mathrm{o}}, \mu \mathrm{m}\end{array}$ & $\begin{array}{c}\text { Strain temperature, } \\
{ }^{\circ} \mathrm{C}\end{array}$ & $\begin{array}{c}\text { Strain rate, } \\
\mathrm{S}^{-1}\end{array}$ & $\begin{array}{c}\text { Average grain diameter } \\
\mathrm{d}, \mu \mathrm{m}\end{array}$ \\
\hline \multirow{2}{*}{1200} & $76.1 \pm 12$ & 1200 & 1.0 & $16.1 \pm 2$ \\
\cline { 3 - 5 } & $34.3 \pm 10$ & 1100 & 1.0 & $10.0 \pm 1$ \\
\hline 1100 & 1100 & 3.6 & $9.8 \pm 2$ \\
\hline
\end{tabular}

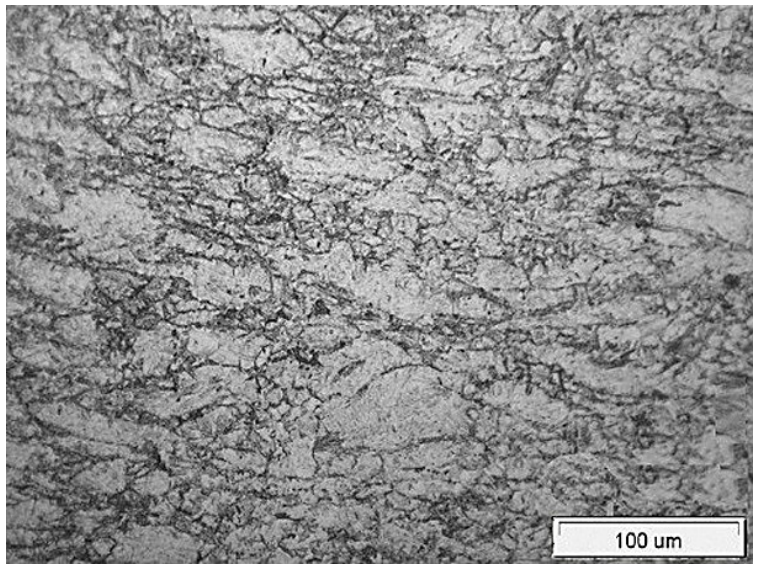

Figure 6. Partially dynamically recrystallized primary austenite grains of the HSLA steel after deformation at $1000{ }^{\circ} \mathrm{C}$ and $\varepsilon^{\circ}=15.9 \mathrm{~s}^{-1}\left(\mathrm{~T}_{\mathrm{A}}=1250{ }^{\circ} \mathrm{C}, \varepsilon=1.2\right)$

austenite grains, which is a structure characteristic of the initial phase of dynamic recrystallization.

In the investigated steel deformed from $\varepsilon=$ 0.268 at an austenitizing temperature of $1200{ }^{\circ} \mathrm{C}$ and a rate $1.0 \mathrm{~s}^{-1}$, fine recrystallised austenite grains were revealed on the background of the primary $\gamma$ grains corresponding to the applied austenitizing temperature (Figure 8a). Under such conditions, the strain of $\varepsilon=0.4$ at $1000{ }^{\circ} \mathrm{C}$ is not sufficient to initiate dynamic recrystallization (Figure $8 b$ ). All the more in case of a compression investigation of the investigated steel at $800{ }^{\circ} \mathrm{C}$ and 900 ${ }^{\circ} \mathrm{C}$ and strain degree $\varepsilon=0.6$, the revealed primary austenite grains only show distinct effects of strain hardening or dynamic recovery, but do not reveal the common symptoms indicating a potential contribution of dynamic recrystallization (Figure 9).

The austenite grain size for the analyzed range of strain parameters due to which the main process resulting in the reduction of hardening in HSLA steel was dynamic recrystallization is shown in Table 2. The structure of austenite inherited by martensite in the investigated steel after compression deformation at $1000{ }^{\circ} \mathrm{C}$ and a rate of $1.0 \mathrm{~s}^{-1}\left(\mathrm{~T}_{\mathrm{A}}=1200{ }^{\circ} \mathrm{C}\right)$ is shown in the microphotograph (Figure 10). The boundaries of dynamically recrystallized austenite grains were observed in the background of martensite plates.

\section{CONCLUSIONS}

The austenitizing temperature before the $\gamma$ to $\alpha$ ' transformation has a decisive impact on the primary austenite grain size in HSLA steel. The investigated steel austenitized at $1100{ }^{\circ} \mathrm{C}$ is characterised by the austenite grains with average diameter of $\mathrm{d}_{0}=$ $34 \mu \mathrm{m}$, and after austenitizing at 1200 and $1250^{\circ} \mathrm{C}$ by grains of $d_{0}=74 \mu \mathrm{m}$ and $83 \mu \mathrm{m}$, respectively. For the investigated microalloyed steel with $\mathrm{Ti}, \mathrm{Nb}$ and $\mathrm{N}$, the size of the dynamically recrystallized $\gamma$ grain decreases as the strain temperature is lowering and increasing. These parameters have a much greater impact on the regrouping and distribution of dislocations resulting in the formation of recrystallization

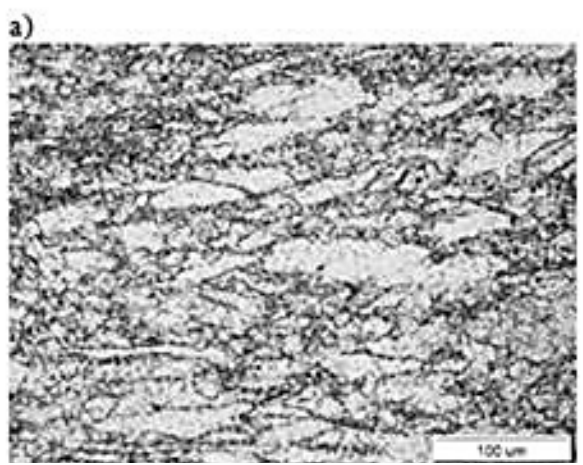

b)

Figure 7. Partially dynamically recrystallized primary austenite grains after deformation at $\varepsilon^{0}=3.6 \mathrm{~s}^{-1}$ and a) $1100{ }^{\circ} \mathrm{C}$, b) $900{ }^{\circ} \mathrm{C}\left(\mathrm{T}_{\mathrm{A}}=1200{ }^{\circ} \mathrm{C}, \varepsilon=1.2\right)$ 
a)

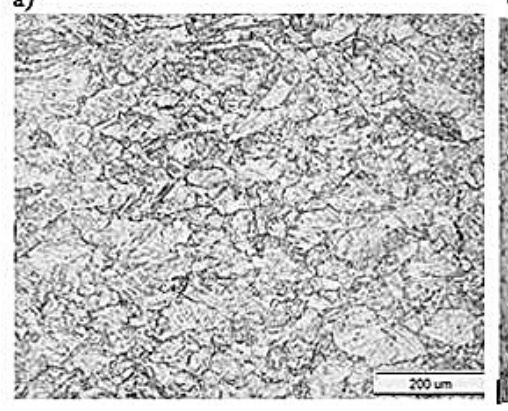

b)

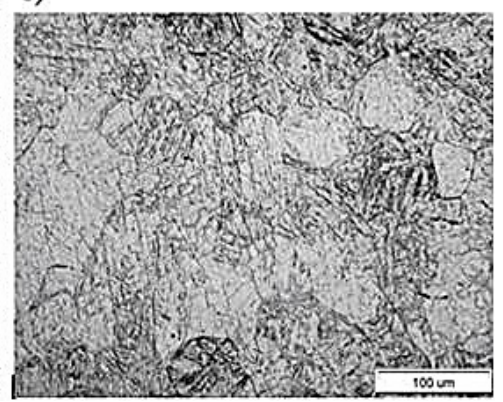

Figure 8. The effect of HSLA steel strain degree and strain temperature on the structure of primary austenite grains: a) $\varepsilon=0.268, \mathrm{~T}_{\text {def }}=1200{ }^{\circ} \mathrm{C}$, b) $\varepsilon=0.4, \mathrm{~T}_{\text {def }}=1000^{\circ} \mathrm{C}\left(\mathrm{T}_{\mathrm{A}}=1200{ }^{\circ} \mathrm{C}, \varepsilon^{0}=1.0 \mathrm{~s}^{-1}\right)$

a)

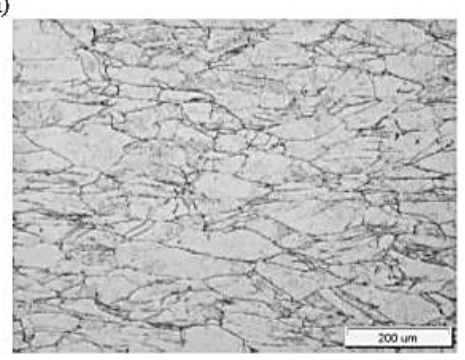

b)

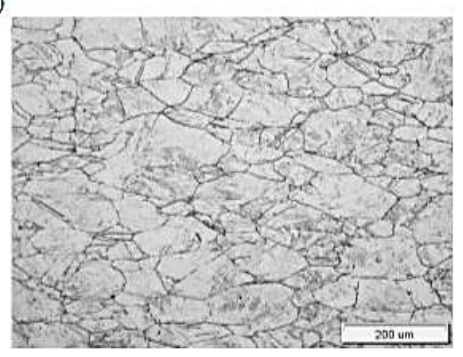

Figure 9. The effect of the HSLA steel strain degree and strain temperature on the structure of primary austenite grains: a) $\left.\varepsilon=0.6, \mathrm{~T}_{\text {def }}=800{ }^{\circ} \mathrm{C}, \mathrm{b}\right) \varepsilon=0.6, \mathrm{~T}_{\text {def }}=900^{\circ} \mathrm{C}\left(\mathrm{T}_{\mathrm{A}}=1200^{\circ} \mathrm{C}\right.$, strain rate $\left.=1.0 \mathrm{~s}^{-1}\right)$, b) $\varepsilon=0,6, \mathrm{~T}_{\text {def }}=900^{\circ} \mathrm{C}\left(\mathrm{T}_{\mathrm{A}}=1200^{\circ} \mathrm{C}, \varepsilon^{0}=1.0 \mathrm{~s}^{-1}\right)$

fronts (grain refinement) than on the rate of their migration (grain growth). The reduction in a strain temperature from 1200 to $1100{ }^{\circ} \mathrm{C}$ at an austenitizing temperature of $1200^{\circ} \mathrm{C}$ and strain rate of $1.0 \mathrm{~s}^{-1}$ allowed the $\gamma$ grain size to be reduced from approx. $16 \mu \mathrm{m}$ to approx. $10 \mu \mathrm{m}$. The increase in strain rate up to $=3.6 \mathrm{~s}^{-1}$ at a strain temperature and an austenitizing temperature of $1100{ }^{\circ} \mathrm{C}$ has resulted in the reduction in austenite grain size to $d=9.8 \mu \mathrm{m}$ in

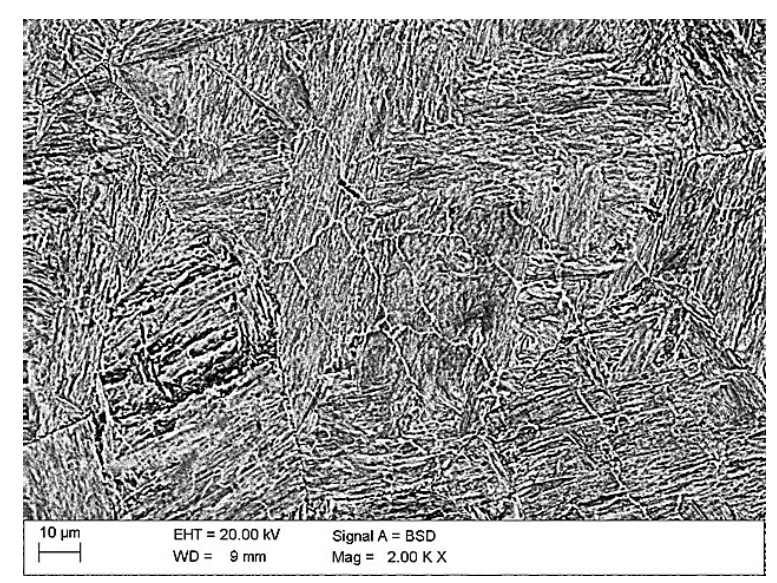

Figure 10. Structure of dynamically recrystallized austenite compared to martensite after deformation of HSLA steel at $1000^{\circ} \mathrm{C}$ and a rate of $1 \mathrm{~s}^{-1}$ followed by water cooling $\left(\mathrm{T}_{\mathrm{A}}=1200{ }^{\circ} \mathrm{C}, \varepsilon=1.2\right)$
HSLA steel. The grain size obtained during dynamic recrystallization does not depend on the primary grain size obtained during austenitizing in the analysed temperature range $\left(1100-1250^{\circ} \mathrm{C}\right)$.

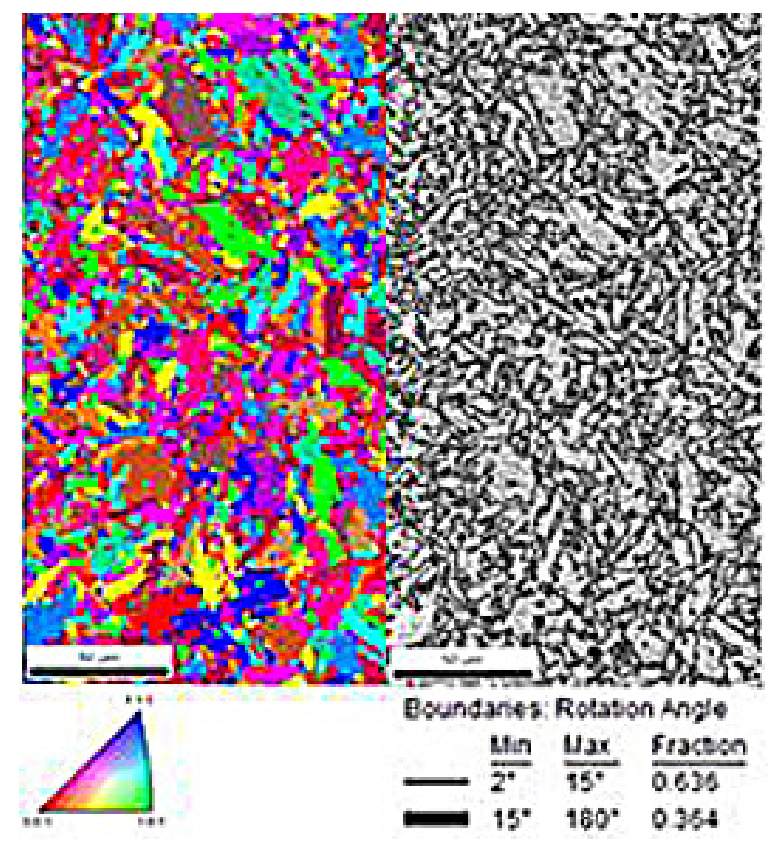

Figure 11. Result of the EBSD analysis carried out for the HSLA steel after deformation at $1000{ }^{\circ} \mathrm{C}$ and a rate of $1.0 \mathrm{~s}^{-1}\left(\mathrm{~T}_{\mathrm{A}}=1200^{\circ} \mathrm{C}, \varepsilon=1.2 /\right.$ water $)$ 


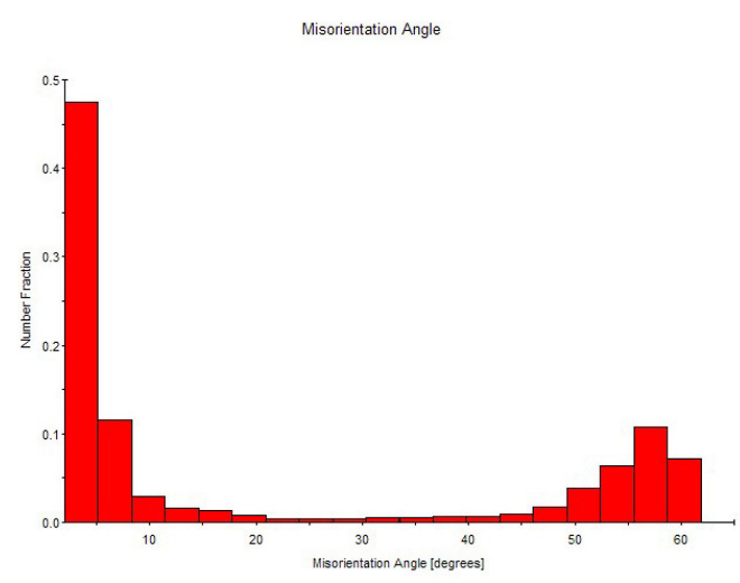

Figure 12. Grain disorientation angle distribution

\section{REFERENCES}

1. Adamczyk J., Ozgowicz W., Wusatowski R., Kalinowska-Ozgowicz E., Grzyb R.: Boron treated microalloyed quenched and tempered plates, their structure and properties. Journal of Materials Processing Technology 64, 1997, 1-8.

2. Adamczyk J., Kalinowska-Ozgowicz E., Ozgowicz W., Wusatowski R.: Interaction of carbonitrides $\mathrm{V}(\mathrm{CN})$ undissolved in austenite on the structure and mechanical properties of microalloyed $\mathrm{V}-\mathrm{N}$ steels. Journal of Materials Processing Technology 53, 1995, 23-32.

3. Akhavan B., Ashrafizadeh F., Hassanli A.M.: Influence of retained austenite on the mechanical properties of low carbon martensitic stainless steel castings. ISIJ Int. 2011, 51, 471-475.

4. Anselmo, N., May J.E., Mariano N.A., Nascente P.A.P., Kuri S.E.: Corrosion behavior of supermartensitic stainless steel in aerated and $\mathrm{CO}_{2}$-saturated synthetic seawater. Materials Scienceand EngineeringA 428, 2006, 73-79.

5. Aquino J.M., Rovere C.A.D., Kuri S.E.: Localized corrosion susceptibility of supermartensitic stainless steel inwelded joints. Corrosion 64, 2008, 35-39.

6. Ashrafi, H.; Shamanian, M.; Emadi, R.; Saeidi, N. A novel and simple technique for development of dual phase steels with excellent ductility. Materials Science and EngineeringA 680, 2017, 197-202.

7. Balart M.J., Davis C.L., Strangwood M.: Fracture behavior in medium-carbon Ti-V-N and V-N microalloyed ferritic-pearlitic and bainitic forging steels with enhanced machinability. Materials Science and Engineering A 328, 2002, 48-57.

8. Bojack A., Zhao L., Morris P.F., Sietsma J.: Austenite formation from martensite in a $13 \mathrm{Cr} 6 \mathrm{Ni} 2 \mathrm{Mo}$ supermartensitic stainless steel. Metallurgical and Materials Transaction A 47, 2016, 1996-2009.

9. Caminga C., Botta Filho W.J., Silva M.L.N., Button S.T.: Strengthening mechanism of $27 \mathrm{MnSiVS} 6 \mathrm{mi}-$ croalloyed steel deformed by four different forging

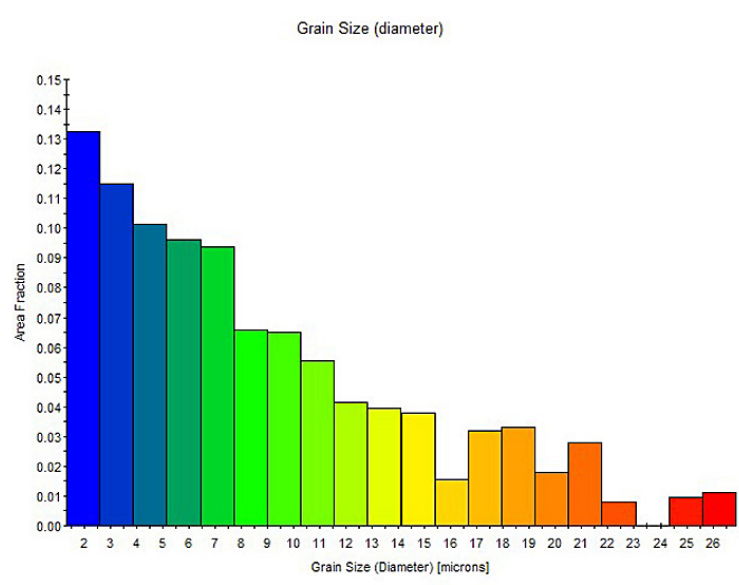

Figure 13. Grain size distribution

processes. Procedia Engineering 10, 2011, 512-517.

10. De Sanctis M., Lovicu G., Valentini R., Dimatteo A., Ishak R., Migliaccio U., Montanari R., Pietrangeli E.: Microstructural features affecting tempering behavior of $16 \mathrm{Cr}-5 \mathrm{Ni}$ supermartensitic steel. Metallurgical and Materials Transaction A 46, 2015, 1878-1887.

11. Deleu E., Dhooge A.: Weldability assessment of thick super-martensitic $13 \mathrm{Cr}$ stainless steel welds made with matching consumables. Weld. World 49, 2005, 34-44.

12. Della Rovere C.A., Ribeiro C.R., Silva R., Baroni L.F.S., Alcântara N.G., Kuri S.E.: Microstructural and mechanical characterization of radial friction welded supermartensitic stainless steel joints. Materials Science and EngineeringA 586, 2013, 86-92.

13. Escobar J.D., Poplawsky J.D., Faria G.A., Rodriguez J., Oliveira J.P., Salvador C.A.F., Mei P.R., Babu S.S., Ramirez A.J.: Compositional analysis on the reverted austenite and tempered martensite in a Ti-stabilized supermartensitic stainless steel: Segregation, partitioning and carbide precipitation. Materials and Design 140, 2018, 95-105.

14. Garcia-MateoC., LópezB., Rodriguez-IbabeJ.M.: Influence of vanadium on static recrystallization in warm worked microalloyed steels. Scripta Materialia 42, 2000, 137-143.

15. GladmanT:: The physical metallurgy of microalloyed steels. The Institute of Materials, London 1997.

16. Gnapowski S., Tsunekawa Y., Okumiya M., Lenik K.: Change of aluminum alloys structure by sonosolidification, Archives of Foundry Engineering 13, 2013, 39-42.

17. GündüzS., AcarerM.: The effect of heat treatment on high temperature mechanical properties of microalloyed medium carbon steel. Materials and Design27, 2006, 1076-1085.

18. Jahazi M., Eghbali B.: The influence of hot forming conditions on the microstructure and mechanical properties of two microalloyed steels. Journal of Materials Processing Technology 113, 2001, 594-598. 
19. Kalashami A.G., Kermanpur A.,Najafizadeh A., Mazaheri Y.: Development of a high strength and ductile $\mathrm{Nb}$-bearing dual phase steel by cold-rolling and intercritical annealing of the ferrite-martensite microstructures. Materials Science and EngineeringA 658, 2016, 355-366.

20. Kalinowska-Ozgowicz E.: Structural and mechanical factors of the strengthening and recrystallization of hot plastic deformation of steels with microadditives, (in Polish), Open\Acces Library vol.20, URLhttp://www.openaccesslibrary.com/index. php?id=97, 2013, 1-246.

21. Kalinowska-Ozgowicz E., Kuziak R., Ozgowicz W., Lenik K.: Kinetics of the precipitation in austenite HSLA steels. Materials and Technologies, 49(5), 2015, 673-679.

22. Kalinowska-Ozgowicz E., Wajda W., Ozgowicz W.: Mathematical modelling and physical simulation of the hot plastic deformation and recrystallization of steel with micro-additives. Materiali in Tehnologije 49, 2015, 69-74.

23. Kuziak R.: Modeling changes in structure and phase transformations occurring in the processes treatment of thermo-plastic steel. Instytut Metalurgii Żelaza (in Polish) Gliwice 2005.

24. Leem D.S., Lee Y.D., Jun J.H., Choi C.S.: Amount of retained austenite at room temperature after reverse transformation of martensite to austenite in an $\mathrm{Fe}-13 \% \mathrm{Cr}-7 \% \mathrm{Ni}-3 \% \mathrm{Si}$ martensitic stainless steel. Scripta Materialia 45, 2001, 767-772.

25. Lian Y., Huang J., Zhang J., Zhang, C., Gao W., Zhao C.: Effect of 0.2 and $0.5 \% \mathrm{Ti}$ on the microstructure and mechanical properties of $13 \mathrm{Cr}$ supermartensitic stainless steel. Journal of Materials Engineering and Performance24, 2015, 4253-4259.

26. Lourenco N.J., Jorge A.M., Rollo J.M.A., Balancin O.: Plastic behavior of medium carbon vanadium microalloyed steel at temperatures near $\gamma \rightarrow \alpha$ transformation. Materials Research3, 2001, 149-146.

27. Ma X., Wang L., Subramanian S.V., Liu C.: Studies on $\mathrm{Nb}$ microalloying of $13 \mathrm{Cr}$ super martensitic stainless steel. Metallurgical and Materials Transaction A 43, 2012, 4475-4486.

28. Mazaheri Y., Kermanpur A., Najafizadeh A.: Microstructures, mechanical properties, and strain hardening behavior of an ultrahigh strength dual phase steel developed by intercritical annealing of cold-rolled ferrite/martensite. Metallurgical and Materials Transaction A 46, 2015, 3052-3062.

29. Nakagawa H., Miyazaki T.: Effect of retained austenite on the microstructure and mechanical properties of martensitic precipitation hardening stainless steel. Journal of Materials Science 34, 1999, 3901-3908.

30. Opiela M.: Thermomechanical treatment of Ti$\mathrm{Nb}-\mathrm{V}-\mathrm{B}$ microalloyed steel forgings. Materiali in Tehnologije 48, 2014, 587-591.

31. Opiela M.: Thermodynamic analysis of the precipitation of carbonitrides in microalloyed steels. Ma- teriali in Tehnologije 49, 2015, 395-401.

32. Opiela M., Grajcar A: Microstructure and anisotropy on plastic properties of thermomechanicaly-processed HSLA-type steel plates. Metals 8, 2018, 1-15.

33. Ozgowicz W., Opiela M., Kalinowska-Ozgowicz E.: Metallurgical products of microalloy constructional steels. Journal of Achievements in Materials and Manufacturing Engineering 44, 2011, 7-19.

34. PadmanabhanK.A., SankaranS.: Fatigue behavior of a multiphase medium carbon V-bearing microalloyed steel processed through two thermomechanical routes. Journal of Materials Processing Technology207, 2008, 293-300.

35. Roberts W., Boden H., Ahblo B.: Dynamic recrystallization kinetics, Metal Science 13, 1979, 195-205.

36. Rodrigues C.A.D., Bandeira R.M., Duarte B.B., Tremiliosi-Filho G., Jorge A.M.: Effect of phosphorus content on the mechanical, microstructure and corrosion properties of supermartensitic stainless steel. Materials Science and EngineeringA 650, 2016, 75-83.

37. Rodriguez-Ibabe J.M.: Thin slab direct rolling of microalloyed steels. Trans. Tech., Publications Ltd, Switzerland 2007.

38. Silva, G.F., Tavares S.S.M., Pardal J.M., Silva M.R., de Abreu H.F.G.: Influence of heat treatments on toughness and sensitization of a Ti-alloyed supermartensitic stainless steel. Journal of Materials Science 46, 2011, 7737-7744.

39. Skobir D.A.: High-strength low-alloy (HSLA) steels. Materials and Technology 45, 2011, 295-301.

40. Skubisz P., Sińczak J., Skowronek T., Rumiński M.: Selection of direct cooling conditions for automotive lever made of microalloyed steel. Archives of Civil and Mechanical Engineering 12, 2012, 418-426.

41. Song Y.Y., Li X.Y., Rong L.J., Li Y.Y., Nagai T.: Reversed austenite in 0Cr13Ni4Mo martensitic stainless steels. Materials Chemistry and Physics 143, 2014, 728-734.

42. Spena P.R., Firrao D.: Thermomechanical warm forging of $\mathrm{Ti}-\mathrm{V}$, Ti-Nb, and Ti-B microalloyed medium carbon steel. Materials Science and Engineering A 560, 2013, 208-215.

43. Xu L., Wang Ch., Liu G., Bai B.: Hot deformation of medium carbon V-N microalloyed steel. Transactions of Nonferrous Metals Society of China 19, 2009, 1389-1394.

44. Ye D., Li J., Jiang W., Su J., Zhao K.: Effect of Cu addition on microstructure and mechanical properties of $15 \% \mathrm{Cr}$ super martensitic stainless steel. Materials Design 41, 2012, 16-22.

45. Zepon G., Nascimento A.R.C., Kasama A.H., Nogueira R.P., Kiminami C.S., Botta W.J., Bolfarini C.: Design of wear resistant boron-modified supermartensitic stainless steel by spray forming process. Materials Design 83, 2015, 214-223.

46. ASTM E112-10 Standard Test Methods for Determining Average Grain Size. 